\title{
Theoretical Analysis of the Integration Development of Moral Education and Technology
}

\author{
Linchuan Zheng \\ College of Chemistry \& Chemical Engineering of China West Normal University \\ Nan Chong, Sichuan Province, China \\ kellyken@126.com
}

\begin{abstract}
Modern information technology provides good technical support for the development of moral education, which is inseparable from technology. In order to effectively explore the scientificity and effectiveness of the integration of moral education and technology, this paper makes a theoretical analysis of the integration of technology and moral education from different perspectives, such as philosophy of technology, epistemology, axiology and practice, based on the theoretical perspective of the integration of moral education and technology. Finally, the article puts forward that the integration of moral education and technology should follow the first principle of people-oriented, the basic principle of unity of science and humanities, and the bottom line principle of coordination between subject and carrier.
\end{abstract}

Keywords_Technology;Moral Education;Integration;Principle

\section{INTRODUCTION}

With the development of modern information technology, technologies such as Internet, big data, new media, artificial intelligence, virtual reality and so on have come into people's vision. These technologies have profoundly changed people's mode of production and lifestyle, also brought unprecedented impact and challenge to moral education, and put moral education in a technology environment. Marx once made such a statement in the face of the torrent of large industrial technology that "the history of industry and the existence of the objectivity that industry has produced are an open book on the essential power of human beings". [1] It is very important to fully understand the logical relationship between moral education and technology, to explore how technology can help moral education, how to develop it, and what inspiration it has. It is of great practical significance to clarify the basic theoretical issues of moral education and technology integration to promote the innovative development of moral education in the new era.

Project Fund: Fundamental Research Fund of China West Normal University (Counselor Project), "Innovative Research on Ideological and Political Education in the Perspective of Big Data Strategy" (Project No. 17F007)

\section{How Is IT Possible: THE LOGICAL BASIS FOR TECHNOLOGY TO HelP MORAL EdUCATION IN COLLEGES AND UNIVERSITIES}

\section{A. What is technology?}

Different scholars at home and abroad have different definitions about the meaning of "technology". Marx's technological thought is scattered in his works. He believes that technology is the way of human transformation of the world, including thinking technology, natural technology and social technology. Yang Jianxue, a scholar, believes that technology is narrow and broad, and narrow technology generally refers to various process operation methods and skills developed on the basis of production practice experience and natural science principles. Broad-sense technology serves social production and human material and cultural needs. It can provide the synthesis of material means, intelligent means and information means for people to utilize and transform nature. [2] The definition of technology in the Dictionary of Science in China is: "Technology serves the needs of social production and human material and cultural life, and is the sum of material, spiritual and information means for human beings to use and transform nature." The "technology" discussed in this paper refers to the broad sense of technology, including available material means, intelligent means and information means, that is, including traditional educational media technology and modern information technology. Specifically, the traditional educational media technology refers to slide, recording, video, projection, television, tape and other technologies. Modern information technology refers to computer technology, digital audio-visual technology, electronic communication technology, network technology, satellite broadcasting technology, remote communication technology, artificial intelligence technology, virtual reality simulation technology, multimedia technology and information superhighway.

\section{B. The Theoretical Basis of Moral Education with Technical Assistance}

1) From the perspective of philosophy of technology, man is the person of technology, which exists in a technological society from the beginning of using tools. In a sense, human development is the development of technology, and the development of human society is the process of creating and applying technological achievements. Technology is not only 
an important part of human civilization, but also a scaffold to construct other forms of civilization. [3] Beginning with the separation of apes from human beings, from the Stone Age to the era of hand tools, from the era of machine to today's era of network and artificial intelligence, virtual reality, Internet of Things, remote login and other technologies have extended human organs and become "prosthetic limbs" of modern people. They constantly promote the breadth and depth of humancomputer interaction, and profoundly because comprehensive and far-reaching changes in the way people live, communicate and think. From the cold machine world to the highly integrated human-machine world, human-machine coexistence, that is, "our love with information machines shows a symbiotic relationship, and ultimately our spiritual marriage with technology." [4] Moral education in human social activities can't be immune to the influence of this "symbiotic relationship", even if we regard today's moral education as a technological environment. Modern technology has constituted the overall environmental background of human existence. Therefore, no matter economic, social, political or ideological research, it will inevitably involve technology, which can't be transferred by anyone's subjective will. [5] Nowadays, with the development of all-media, self-media, mobile network and other technologies, moral education is tightly wrapped in them. Educators who want to gain vitality and endogenous motive force for development can only put themselves in the thinking concept of technological vision and make full use of technology to promote ideological and political education.

2) From the perspective of epistemology, technology is the product of social development, which is essentially a purposeful mode of human activity, and also the basic expression and extension of human essential power. It is also a means and method, with the characteristics of super-space-time, fast, dynamic, vivid, multi-directional, complex and so on. It makes a profound impact on people and human society. As far as moral education is concerned, firstly, technology has triggered the transformation of moral education thinking and concepts, which has not only changed the way both sides of education understand and understand the world, but also brought about the global knowledge sharing. Secondly, technology has changed the carrier and environment of education, making the whole education in a strong technological environment, impossible to preserve its own purity. Thirdly, technology has made great changes in the means and methods of moral education, resulting in more flexible and diverse educational methods, more efficient educational effects, more comprehensive and objective evaluation of education, and revolutionary support for the theory and practice of moral education.

3) From the perspective of axiology, the value of technology in moral education is mainly embodied in social value and individual value. Social value is that technology has greatly influenced people's spiritual world and raised people's ideological level. Specifically, the development of technology promotes people to abandon ignorance and form a scientific world outlook, improves the breadth and depth of people's understanding, and the ability to explore knowledge. It also changes people's way of thinking, puts forward new moral requirements, and forms a new philosophy of technology and instrumental rationality. From the perspective of individual value, technology meets the individual needs of both educators and educatees. On the one hand, new technological means provide educators with a brand-new educational carrier and environment, expand the content and form of education, constantly innovate the education model, micro-class, flip-over classroom, mu-class and other educational models constantly emerge, making full-time multi-dimensional interaction and personalized education come true. On the other hand, it provides a space platform for educatees to learn independently and communicate with each other. It extends the space-time scope of learning, leisure, games and classes, and makes it possible to study and live beyond time and space.

4) From the perspective of practice theory, the application of technology in various fields of moral education has developed with the development of moral education, and achieved remarkable results, which provided a strong practical basis for technology to help moral education. At present, the practices that have been carried out include: using big data to analyze and evaluate data; using network and modern media technology to carry out ideological and political theory education and teaching, using deep learning to carry out the analysis of learning time, focus and behavior trajectory, using virtual reality to carry out simulation teaching and experiential teaching, using network technology to carry out public opinion monitoring and network ideological and political education, etc It has become a reality. In the future, with the rapid development of artificial intelligence, Internet of Things and wireless network, there will be more advanced technology to help moral education, making everything impossible possible.

\section{How to Develop: The Evolution Process of TECHNOLOGY HELPING MORAL EDUCATION}

Technology assists moral education in Colleges and universities, which is synchronized with and resonates with the development of moral education discipline. The integration of technology and moral education can be divided into four stages according to the stage characteristics of the development of moral education. They are the stage of exploration, the stage of rapid development, the stage of comprehensive deepening and the stage of innovation and development.

\section{A. Exploratory Trial Phase (1984-1994)}

The exploratory trial stage (1984-1994) was accompanied by the establishment of moral education specialty and discipline. In this stage, the viewpoints and methods of Western system theory were introduced into education, and the combination of various audio-visual media was advocated. A large number of audio-visual media entered the classroom, such as slides, projections, television, videos and tapes. In 1994 the Central Ministry of Propaganda promulgated the Outline for the Implementation of Patriotic Education. Article 19 of the Outline pointed out that "according to the characteristics of young people, we should pay attention to the use of film and television, books and magazines, music, drama, fine arts, story clubs and other forms to provide rich and vivid patriotic textbooks for the majority of young people." It has further aroused the upsurge of using various audio-visual media in 
moral education. The application of audio media from silent media has greatly enhanced the attraction of moral education.

\section{B. Rapid Development Phase (1995-2004)}

During the period of rapid development (1995-2004), a complete scientific system from undergraduate, master to doctor was established. Some scholars began to explore the use of media in education and teaching. The emerging information technology has provided abundant teaching means for modern education, such as multimedia teaching technology, interactive two-way video and audio technology, one-way prefabrication and video technology, network-based teaching technology, etc. Since 2000, some people have called the Internet the "fourth media" after newspapers, radio and television. Lin Tianning and other scholars discussed the impact of "the fourth media" on moral education of college students and put forward preliminary countermeasures, becoming a group of scholars who studied the impact of the Internet on moral education earlier in the academic circles. Since then, multimedia technology, Web 2.0 technology and information technology have been applied to moral education. The integration of moral education and technology has entered a period of diversification, vividness and networking, which further improves the attraction of moral education.

\section{Comprehensive Deepening Phase (2005-2015)}

In the comprehensive deepening stage (2005-2015), the First-Level Discipline of moral education was formally established. With the development of discipline, the integration of technology and education is more flourishing. From China's formal access to the Internet to 2015, the statistical report on the development of Internet in China shows that there are 680 million Internet users. At this stage, from WEB 2.0 to WEB 3.0, cloud computing, big data and other emerging information technologies have entered the field of moral education. Big data, virtual reality, artificial intelligence and other technologies have brought moral education great impact. Network moral education has become a branch of education. At this time, new education models such as multimedia teaching, network teaching, coursework, flipping classroom and micro-class have emerged, which has effectively enhanced the pertinence and effectiveness of moral education.

\section{Innovation Development Phase (2016-)}

In the stage of innovation and development (2016-present), with the innovation and development of moral education and the rapid upgrading of new media and network technology, the integration of modern information technology and moral education has become irresistible, which is not only the inevitable requirement of the development of the times and situation, but also the inherent demand of moral education itself. In terms of practical application, some scholars have discussed the introduction of big data into college students' precise subsidies, personalized education, teaching evaluation, object intelligence portraits, etc. Some have carried out network psychological counseling, honesty education, Thanksgiving Education and so on. In terms of theoretical research, scholars have discussed the functions, values, strategies, paths, methods, effect evaluation and existing problems of the integration of Internet, big data, self-media, micro-media, virtual reality and moral education. They have also discussed network culture, network morality, cultural product development, innovation of discourse mechanism and network public opinion Situation monitoring and so on. In the future, big data, artificial intelligence, Internet of Things and wireless network will be further developed. At that time, superspace technology, full interconnection and full media will enter people's lives. The era of 5G network and Web4.0 knowledge distribution will also come soon. Change and innovation will become the eternal theme in the future. How can moral education achieve better integration with technology to Innovation-driven development is the challenge it faces in the new era and new stage.

\section{WHAT'S THE INSPIRATION: THE PRINCIPLE OF}

\section{INTEGRATION OF MORAL EDUCATION AND TECHNOLOGY}

Throughout the process of integration of technology and moral education, we can find that technology can enhance the pertinence and effectiveness of moral education, enhance the attraction and appeal of moral education, and provide good help to promote the growth of students. But technology is also a double-edged sword, which brings both opportunities and severe challenges. The integration of Ideological and political education and technology should give full play to the advantages of technology, and follow the principle of integration of technology and moral education according to circumstances, so as to achieve good results of co-operation and coordinated development.

\section{A. The Principle of Human Orientation}

Technology originates from people's subjective needs and practical activities. Its fundamental purpose is to promote human liberation and free and all-round development. However, the development of science and technology liberates human beings from heavy physical labor, and at the same time makes human beings more and more dependent on technology. The result of people's willingness to participate in and implement technology has been functionalized, becoming human resources and technical staff. They can no longer face up to their true nature, and the meaning of human life has been uprooted. [6] When human beings are controlled by technology, they violate the true intention of technology. Technology not only promotes human development, but also alienates human beings. This is a result that nobody wants to see. The basic goals of moral education and technology are the same. They all refer to the free and all-round development of human beings. The free and all-round development of human beings includes two meanings: one is the free development of human beings, the other is the all-round development of human beings. According to the essence of human development in the future society stipulated by Marxism, it refers to the process and realm in which every real person gets rid of and surpasses all kinds of internal and external restrictions and restraints, and achieves the universal improvement and coordinated development of human relations, abilities, qualities and individualities. [7] That is to say, "Man should possess all his essence". This kind of possession is free from any restraint and restraint, and is free from all kinds of external and internal 
limitations and restrictions that restrict human development. This kind of possession is also comprehensive, and the prerequisite is the possession of a complete person, not a person alienated by technology. Therefore, people-oriented is its primary principle from the point of view of starting point and goal of technology to promote the all-round and free development of human beings.

\section{B. The principle of the unity of science and humanity}

The tendency of over-technicalization leads to the deviation between science and technology and humanities. On the contrary, it makes mankind fall into the predicament of survival and development crisis, which moral education does not want to see. Science and humanities are of the same origin because they both originate from human practice and serve the development of human practice. Therefore, they should promote each other and integrate into the educational process. As early as more than a hundred years ago, Marx asserted that "natural science will include science about human beings in the future, just as science about human beings includes natural science: it will be a science...Man is the direct object of natural science... Nature is the direct object of human science." [8] Therefore, the process of moral education is the integration of science and technology and humanities. Moral education should not only develop people's knowledge, ability and wisdom, but also pay attention to people's spirit and morality. It neither emphasizes technology as the only tool, nor rejects the rational help of technology.

\section{Bottom Line Principle of Coordination between Subject and Carrier}

In the process of technology-assisted moral education, it is necessary to clarify the main position of moral education and the carrier role of technology, and to clarify their primary and secondary roles in order to maintain their true qualities and adhere to the bottom line of integration. Firstly, moral education should play a leading role, set the direction and goal, and control the general tone and route of education. Secondly, technology provides supportive means to assist in the design, resource development, utilization, management and effectiveness evaluation of moral education process, because it is itself an educational means and carrier, regulated by moral education. Only by correctly grasping the status relationship between the subject of moral education and the technical carrier can we prevent moral education from being "technicalized" and achieve the coordination between the subject and the carrier.

\section{SUMMARY}

To sum up, technology-assisted moral education is a historical and practical process. They are mutually reinforcing. Technology development improves the effectiveness and pertinence of moral education. Similarly, the development and demand of moral education also promotes the continuous progress of technology development. We can achieve the optimal integration and innovative development of moral education technology, as long as we fully recognize the internal relationship between technology and moral education, and follow certain principles.

\section{REFERENCES}

[1] Karl Marx,Engels. Complete works of Marx and Engels (Vol. 42) [M] Beijing: People's Publishing House, 1980, 127.

[2] Yang Gaixue. Educational Technology Course: The Theory and Practice of Teaching and Learning in the Information Age [M]. Beijing Normal University Press, July 2010

[3] Wang Bolu. An Analysis of the Technological Problem of Man in the Broad View of Technology [J]. Dialectical Communication of Nature, 2005, (6).

[4] Michael Helm Kim Woolen. From interface to cyberspace: the metaphysics of virtual reality [M]. Liu Gang, Translated. Shanghai: Shanghai Science and Technology Education Press, 2000.

[5] Xie Yujin. Constructing Technical Vision: An Important Issue of Network Ideological and Political Education [J]. Modern Distance Education, 2009, (5): 56-60.

[6] Li Hongwei. Traps of Modern Technology [M]. Beijing: Science Press, 2007:27.

[7] Chen Zhishang. On the Free and All-round Development of Human Beings [M]. Beijing: People's University Publication House, 2004.

[8] Karl Marx,Engels. Complete works of Marx and Engels (Vol. 42) [M]. Beijing: People's Publishing House, 1980, 129. 